and spleen and may precipitate covert or overt pancreatitis. Such patients may also develop disfiguring and painful eruptive xanthomata, which are subject to ulceration, discharge, and infection. These patients need active treatment. Dietary restriction of fat, carbohydrate, and, in particular, alcohol will usually rapidly lower triglyceride concentrations with early resolution of visceral symptoms and regression of cutaneous lesions. There may be some justification for using lipid-lowering agents in the few patients with a persisting large rise in serum triglyceride concentrations despite dietary compliance and weight reduction.

These general principles provide a basis for an approach to the patient with proved hyperlipidaemia. The cornerstone must be the intention to treat the patient rather than his biochemical results. Firstly, and most important, the patient should be given detailed dietary advice with a target to aim at if overweight. Simply handing out leaflets and "calorie counters" is not enough. Most doctors have access to the skills of health service dietitians, either community based or in a local hospital, and they should use this service early.

Patients who fail to comply with diet sufficiently to achieve their optimum body weight are unlikely to respond satisfactorily to drug treatment. Prescription of drugs is certainly inappropriate in the first instance in hyperlipidaemia without first providing detailed dietary advice and making sure such advice is understood and followed. A year's treatment with lipid-lowering agents costs from about $£ 40$ for clofibrate to $£ 400$ for ion-exchange resins in minimum adult doses, while dietary treatment is generally both cheap and free of adverse effects.

Monitoring the treatment of patients with hyperlipidaemia requires assessment of clinical symptoms and signs, if any, body weight, and measurement of fasting plasma cholesterol and triglyceride concentrations. The plasma cholesterol concentration is not, however, a simple risk factor, since it includes the high-density lipoprotein (HDL) cholesterol, which is thought to exert a protective influence. ${ }^{6}$ The LDL: HDL ratio may be a more reliable risk factor, particularly if the $\mathrm{HDL}_{2}$ subfraction is measured. ${ }^{7}$ Thus the notion of a regimen or drug that is cholesterol lowering is simplistic, since in some instances both LDL cholesterol ("bad") and HDL cholesterol ("good") may be reduced. Furthermore, the real test of a treatment is the effect on the whole patient not just on biochemical changes in the plasma.

Patients will need referral to specialist clinics with an interest in lipid disorders when their response to diet is poor or the primary physician is unhappy about proceeding further on his own. Such clinics give further clinical assessment and advice from attending dietitians and can often provide extra psychological pressure to follow this advice. They also provide the opportunity for further investigation. Since the staff of lipid clinics see many patients with hyperlipidaemia and are familiar with current ideas they are in the best position to advise whether or not to start drug treatment.

The drugs used in the treatment of hyperlipidaemia have controversial clinical benefits and they are likely to be used for very long periods by patients. Ideally, therefore, they should be prescribed only in properly controlled trials designed to clarify their benefits and risks. Attention has recently been drawn to the finding of electrocardiographic abnormalities, particularly an increased $\mathrm{Q}-\mathrm{T}$ interval, in patients receiving probucol long term. ${ }^{8}$ What this means clinically in terms of real risk in man remains uncertain. ${ }^{9}$ The finding should serve, however, as a reminder that few drugs are entirely without risk, particularly if taken over long periods. Prescribing and taking drugs may seem simple but requires careful and $\underline{\underline{\sigma}}$ informed selection of those patients in whom benefits are likely to exceed possible risks.

Patients with hyperlipidaemia present important questions and opportunities in the primary prevention of major diseases. We will not answer these questions by treating disorders about which we know little with drugs which we are not sure are effective unless we organise such treatment to provide information. Drugs which are potentially important if used selectively will, unless we are careful, be submerged one by one by the same tide of criticism which has almost swamped clofibrate-a tide generated by excessive and inappropriate prescribing.

BRENDAN M BUCKLEY Senior registrar

ALAN M Bold

Consultant chemical pathologist

Lipid Clinic,

Clinical Chemistry Department,

Queen Elizabeth Hospital,

Birmingham B15 2TH

1 Beaumont JL, Carlson LA, Cooper GR, Fejfar Z, Fredrickson DS, Strasser T. Classification of hyperlipidaemias and hyperlipoproteinaemias. Bull WHO 1970;43:891-915.

2 Lewis B. The hyperlipidaemias: clinical and laboratory practice. London: Blackwell Scientific Publications, 1976.

${ }^{3}$ Chait A, Brunzell JD. Hyperlipidemias. Medicine International 1981 ; 1 359-63.

${ }^{4}$ Rifkind B, Boor R. The Lipid Research Clinics Coronary Primary Prevention Trial. In: Fumagalli R, Kritchevsky D, Paoletti R, eds. Drugs affecting lipid metabolism. Amsterdam: Elsevier/North Holland, 1980:151-7.

5 The Coronary Drug Project Research Group. Clofibrate and niacin in coronary heart disease. $\mathcal{F} A M A$ 1975;231:360-81.

6 Miller GJ, Miller NE. Plasma-high-density-lipoprotein concentration and development of ischaemic heart-disease. Lancet $1975 ; \mathrm{i}: 16-9$.

${ }^{7}$ Miller NE, Hammett F, Saltissi S, et al. Relation of angiographically defined coronary artery disease to plasma lipoprotein subfractions and apolipoproteins. $\mathrm{Br}$ Med $\mathcal{F} 1981 ; 282: 1741-4$.

${ }^{8}$ Troendle G, Gueriguian J, Sobel S, Johnson M. Probucol and the QT interval. Lancet 1982;i:1179.

${ }^{9}$ Martz BL. Probucol and the QT interval. Lancet 1982 ;i:1365.

\section{Immunisation of infants at high risk of hepatitis $B$}

Hepatitis B virus is maintained in populations by the existence of a symptomless carrier state. Transmission from highly infective carrier mothers to their newborn by contamination with blood at birth helps to perpetuate the infection since neonates (probably because of the immaturity of their immune systems) usually respond by developing persistent symptomless carriage of hepatitis $B$ virus.

This type of transmission is common in areas with a high prevalence of carriage of hepatitis B virus in the populationfor example, south-east Asia, where the proportion is $10-20 \%$ -and rare where it is low-for example, north-west Europe, where it is $0 \cdot 1-0.5 \%$. The risk to the newborn is also influenced by ethnic differences in the infectivity of carriers. High prevalence and infectivity combine to present the greatest risk to Chinese infants, with a progressive decline in order of risk to the newborn in Africans, Asians, and Caucasians-in whom highly infective carriage of hepatitis B virus is rare. ${ }^{1}$

The infectivity of blood which contains hepatitis B surface antigen (HBsAg) can be gauged by serological tests. Blood containing hepatitis e surface antigen ( $\mathrm{HBeAg}$ ) is highly infective; blood which gives negative results for $\mathrm{HBeAg}$ and 
its antibody (anti-HBe) is of intermediate infectivity; and blood which contains antibody to $\mathrm{HBeAg}$ is of low infectivity. Infants of mothers with this antibody rarely develop persistent carriage of hepatitis $B$ virus. ${ }^{2}$

Though infection with hepatitis B virus acquired at birth seldom does any apparent harm in early life, it is associated with serious liver disease in later years. Large prospective studies in Taiwan have confirmed the findings of case-control studies elsewhere by showing that the death rate among men aged 40-60 who were carriers of $\mathrm{HBsAg}$ was three times higher than in controls; almost all of the extra deaths among carriers were due to cirrhosis or primary carcinoma of the liver. Investigations of families suggest an association between hepatitis $B$ virus infections acquired at birth and the later development of primary carcinoma of the liver. ${ }^{3-5}$

Though several therapeutic agents are being investigated, at present the carrier state cannot be terminated once it has been allowed to develop. Specific hepatitis B immunoglobulin given promptly after birth and repeated at intervals will, however, prevent persistent carriage in most exposed infants, usually by modifying the infection and promoting active immunity. In a large controlled trial in Taiwan hepatitis B immunoglobulin given at birth and repeated twice at intervals of three months had a protective efficacy of about $75 \%{ }^{6}$ The results of a small trial in the Netherlands suggested that hepatitis B immunoglobulin at birth with six further doses at monthly intervals gave greater protection. ${ }^{7}$ Studies are in progress abroad of the efficacy of combinations of hepatitis B immunoglobulin and hepatitis $\mathbf{B}$ vaccine in preventing infection of infants with hepatitis $B$ virus. Meanwhile the use of hepatitis B vaccine for infants of less than 6 months is not licensed in either the United States or Britain and, for the present, hepatitis B immunoglobulin alone is recommended for prevention.

In Britain the newborn at high risk are those of nonCaucasian ethnic origin and the infants of the small number of women who develop acute hepatitis B in late pregnancy. Estimates based on country of birth of the mother suggest that among the 50000-60000 infants born each year to non-Caucasian women about 400 will become persistent carriers of hepatitis B virus after exposure at birth.

Hepatitis B immunoglobulin is available in Britain for infants of women who develop hepatitis B in the last trimester of pregnancy. Supplies are adequate to provide prophylaxis for infants at high risk of infection from carrier mothers, but experience has shown that achieving the desired protection with routine immunisation is more difficult than in a field trial among a selected population, where conditions can be arranged to promote the most favourable outcome. Close co-operation among specialists in several disciplines is essential for any measure of success in preventing perinatally acquired hepatitis B. Firstly, antenatal serological screening tests are needed to identify those patients of non-Caucasian ethnic origin (and the Caucasian patients whose histories suggest the possibility of hepatitis B virus carriage), whose newborn infants will be at risk and require protection. This requires collaboration between obstetricians (including general practitioners who provide complete obstetric services) and microbiologists. Generally the tests will be undertaken at the laboratories to which obstetricians usually send specimens for HBsAg tests, but in case of difficulty arrangements may be made (subject to the availability of resources) with one of the laboratories of the Public Health Laboratory Service. Liaison between obstetricians and paediatricians is another essential. As paediatricians undertake responsibility for the administra- tion of prophylaxis they need to be informed of the expected birth of an "at-risk" infant and alerted to the delivery. Persuading mothers of the need to bring their infants for subsequent doses of hepatitis B immunoglobulin will require much effort in paediatric departments, and, when there are language or social problems, help may be needed from health visitors, the social services, or voluntary bodies. In practice, no paediatrician is likely to have more than one or two of these infants under his care at any time.

A specific surveillance programme has now been set up to provide a framework within which all those concerned may work, so ensuring that appropriate doses of hepatitis B immunoglobulin are to hand when required and providing an assessment of the protection given by this programme throughout the country. The surveillance will be co-ordinated at the Public Health Laboratory Service Epidemiological Research Laboratory (Hepatitis), Central Public Health Laboratory, Colindale Avenue, London NW9 5HT (telephone 01-205-7041 extension 267). A detailed description of the surveillance procedures may be had on request.

Sheila PolakofF

Consultant Epidemiologist,

Public Health Laboratory Service,

Epidemiological Research Laboratory,

Central Public Health Laboratory,

London NW9 5HT

1 Derso A, Boxall EH, Tarlow MJ, Flewett TH. Transmission of HBsAg from mother to infant in four ethnic groups. $B r$ Med 7 1978; :949-52.

${ }^{2}$ Beasley RP, Trepo C, Stevens CE, Szmuness W. The e antigen and vertical transmission of hepatitis B surface antigen. Am $\mathcal{F}$ Epidemiol 1977;105:94-8.

3 Beasley RP, Lin C-C, Hwang L-Y, Chien C-S. Hepatocellular carcinoma and hepatitis B virus; a prospective study of 22707 men in Taiwan. Lancet 1981 ;ii:1129-32,3.

${ }^{4}$ Blumberg BS, London WT. Hepatitis B virus and the prevention of primary hepatocellular carcinoma. $N$ Engl f Med 1981;304:782-4.

5 Sung J-L, Chen D-S. Maternal transmission of hepatitis B surface antigen in patients with hepatocellular carcinoma in Taiwan. Scand $\mathcal{F}$ Gastroenterol 1980;15:321-4.

${ }^{6}$ Reesink HW, Reerink-Brongers EE, Lafeber-Schut BJTh, KalshovenBenschop J, Brummelhuis HGJ. Prevention of chronic HBsAg carrier state in infants of $\mathrm{HBsAg}$-positive mothers by hepatitis B immunoglobulin. Lancet $1979 ; \mathrm{ii}: 436-7,8$.

Beasley RP, Hwang L-Y, Lin C-C, et al. Hepatitis B immune globulin (HBIG) efficacy in the interruption of perinatal transmission of hepatitis B virus carrier state. Initial report of a randomised doubleblind placebo-controlled trial. Lancet 1981 ;ii:388-93.

\section{Smoking still kills}

Last week some rather muted national press headlines told readers that under a new voluntary agreement the tobacco industry is to cut spending on advertising on posters and in cinemas; it is to spend $£ 11$ million on health promotion research; and the warnings on cigarette packets are to be larger. Government ministers gave the clear impression that by agreeing to these changes, which also include controls on video advertising, the industry had done all that could reasonably be expected of it.

The $£ 11$ million is to fund a new body, the Health Promotion Research Trust, which will commission, fund, and publish the results of research into means of encouraging young people to adopt a more responsible attitude to promoting and maintaining their health. The tobacco industry has insisted, however, that the trust will not fund research "designed directly or indirectly to examine the use and effects of tobacco products."

Speaking to journalists on 27 October (see $\mathrm{p}$ 1347) $\mathrm{Mr}$ Kenneth Clarke, the Minister for Health, explained that the 